\title{
Beyond TTM and ABC: A Practice Perspective on Physical Activity Promotion for Adolescent Females from Disadvantaged Backgrounds
}

\author{
Ellyse Hopkins ${ }^{1} * *^{\mathbb{D}}$, Nicola Bolton ${ }^{2}$, David Brown $\left.{ }^{1}{ }^{(}\right)$, Nic Matthews ${ }^{2}$ and Melissa Anderson ${ }^{3}$ \\ 1 School of Sport and Health Sciences, Cardiff Metropolitan University, Cardiff CF5 2YB, UK; \\ dbrown@cardiffmet.ac.uk \\ 2 Cardiff School of Management, Cardiff Metropolitan University, Cardiff CF5 2YB, UK; \\ njbolton@cardiffmet.ac.uk (N.B.); nmatthews@cardiffmet.ac.uk (N.M.) \\ 3 Valleys Gymnastics Academy, Newport NP11 3AG, UK; melissa.vgagymnastics@outlook.com \\ * Correspondence: ehopkins@cardiffmet.ac.uk
}

Received: 29 September 2020; Accepted: 14 October 2020; Published: 18 October 2020

\begin{abstract}
This paper builds on a growing body of literature on the promise of practice theory in understanding and promoting behavior change in society and develops upon Blue (2017) and Spotswood et al.'s (2019) rationale for evolving theories of practice into the domain of contemporary physical activity research. We begin by considering the intersectional nature of the problem. Statistics reveal that physical activity gradients exist based on gender, as well as socio-economic position. Women, girls, and disadvantaged populations report lower levels of activity than more affluent males and females. More problematic still is what StreetGames (2017) call the "double jeopardy", where these characteristics intersect, intensifying the negative gradient. Our argument then comprises three parts. First, we provide a critical discussion of intervention studies seeking to transform exercise behavior amongst these populations. The issue we identify is that studies typically rely on behavior change models, such as the Transtheoretical Model (TTM) and the ABC framework. However, these models tend to take insufficient account of the practical and social aspects of behavior change in physical activity, and thus their subjects often succumb to value-action gaps (Shove, 2010). Second, in contrast, we propose that practice theory provides a promising alternative theoretical lens for promoting behavior change in disadvantaged and often resistant populations. Third, the paper highlights a range of conceptual considerations for exploring the relationship between young, disadvantaged women and physical activity, as well as the development of tangible solutions to improve participation.
\end{abstract}

Keywords: practice theory; social practices; physical activity; women; disadvantaged communities; behavior change; social change

\section{Introduction}

In recent years, physical activity (PA) has become a primary focus of health promotion within the World Health Organization (WHO) [1]. This focus is mirrored throughout many societies by various organizations, due to the far-reaching benefits of PA and its capability for fighting morbidity [2]. Reducing inactivity has thus become a public health priority [3], aided by the identification of groups within society who exhibit higher levels of inactivity compared to the general population [4].

The likelihood of inactivity intensifies when social disadvantages are co-present. These phenomena are illuminated by Crenshaw's [5] concept of intersectionality, whereby prejudice and disadvantage not only overlap but also interact-so much so that theorists of intersectionality, like Crenshaw, maintain they should be studied together rather than separately. One example of the issue of intersectionality has been coined by the idea of "double jeopardy" for PA participation [6]. Double 
jeopardy refers to the lower PA levels exhibited by young females who are also considered economically disadvantaged, two prevalent target groups within public health promotion $[7,8]$. Double jeopardy, as a form of intersectionality, remains prominent, with those experiencing multiple adverse social factors (with regards to PA) likely to be at more significant risk of ill-health when compared to those experiencing one factor alone. More precisely and specifically, recent data from Sport England suggests that in the English context, $26 \%$ of women are considered to be physically inactive. Moreover, just $39 \%$ of girls aged 16 or below can be classed as "active every day" or even "active across the week", meaning that there is a significant percentage of young women not engaging with physical activity $[9,10]$. Meanwhile, those experiencing economic disadvantage were reported 17\% more likely to be inactive than their more affluent counterparts, with 33\% of those in England considered disadvantaged classed as inactive [9]. Work by StreetGames [6] suggested that just 25\% of young, disadvantaged women reached UK guidelines for PA participation. Therefore, the concepts of intersectionality and double jeopardy are useful for helping to identify the group most at risk from the impacts of low levels of PA. The question that then arises is how we engage with this group to promote PA in effective ways.

This paper builds on Blue [11] and Spotswood et al.'s [12] rationales for utilizing theories of practice in the domain of contemporary PA research. Our argument comprises three parts. First, we provide a critical discussion of the current theoretical model most often used by intervention studies seeking to transform exercise behavior amongst these populations. We identify how these studies typically rely on behavior change models, such as the Transtheoretical Model (TTM) and the $\mathrm{ABC}$ framework. We contend that these models tend to take insufficient account of the structural social aspects of behavior change in physical activity, and thus, while structural barriers are sometimes identified, their subjects are accorded too much agency in overcoming these barriers and thereby often succumb to value-action gaps [13]. Second, in contrast, we propose that practice theory provides a promising alternative theoretical lens for promoting behavior change in disadvantaged and often PA-resistant populations, due to its capability to access the key social processes often overlooked by the aforementioned models. Third, the paper highlights a range of conceptual considerations for using practice theory to explore the relationship between (in the case of our work) young, disadvantaged women and physical activity, as well as the development of tangible solutions to improve participation.

\section{Limitations of Previous Intervention-Focused Research}

Existing PA participation research comprises both exploratory and intervention-based studies. Exploratory studies have produced an invaluable body of research which has identified numerous barriers to PA. For example, Whitehead and Biddle [14] identified seven themes, representing adolescent girls' perceptions of PA and what mediates their involvement; (1) perceptions of femininity, (2) self-presentational concerns, (3) changing priorities, (4) lack of motivation and appreciation of the benefits, (5) the desired structure of PA, (6) parental support, and (7) enjoyment-findings that have been supported and further developed by researchers over time [15,16]. Other studies exploring barriers to PA for disadvantaged groups report factors such as time, income, self-esteem, functional capacity, support networks, and choice of activities on offer $[17,18]$.

In contrast, intervention studies are often designed to relieve specific barriers in an attempt to improve participation [19]. Many intervention studies implicitly and explicitly rely on behavior change models, including the TTM or the ABC framework $[13,20]$. Due to the critical need to understand disengagement from PA, a number of projects have been conducted on the efficacy of interventions that seek to increase exercise adherence [21,22] and interventions with adolescent females and disadvantaged groups, specifically $[23,24]$. Despite their widespread use, these and other evaluations suggest that the success of such studies transforming exercise behavior is at best partial [25]. We consider this to be due to the framing of the underlying theoretical models that focus on static relationships between structures and agents, with limited attention paid to the mediation between the two, resulting in an over-emphasized model of agency that is insufficiently connected to the dynamic structural social processes of everyday life. Examples of interventions based on such premises include the use of 
personalized goals and rewards and the use of personal technology, such as pedometers, to improve physical activity participation [26,27]. In what follows we address this issue in more detail.

\subsection{The Transtheoretical Model for Behavior Change}

Used heavily in health-related research, the multidimensional TTM proposes five linear stages of change that individuals move through when modifying their behavior, mediated by factors such as self-efficacy and decisional balance. The stages are (1) pre-contemplation, (2) contemplation, (3) preparation, (4) action, and (5) maintenance [28]. Following the "pre-action" stages, individuals can either maintain the new behavior or terminate it. While success has been illustrated for the TTM in influencing the adoption of positive behavior change across various health contexts [29,30], PA contexts contain a somewhat mixed set of findings, raising questions over its appropriateness. Nonetheless, the model continues to be widely used. For example, an early review by Adams and White [31] concluded that while the TTM benefitted PA levels in some ways in the short-term, there was a far smaller chance of any significant change in the long-term. Here, long-term was equated to six months or more, a measurement supposedly representing an enduring change. In the context of encouraging lifelong participation, this timeframe is problematic. The TTM's effectiveness in PA interventions has also been questioned by Bridle et al. [32], Callaghan, Khalil, and Morres [33], and Hutchison, Breckon, and Johnston [34], with the latter concluding that almost all of the PA interventions included in their systematic review of the TTM were guilty of poor development and implementation of the model. These studies do not accurately represent every dimension of the model, and consequently its efficacy in transforming exercise behavior could not be determined or understood in terms of cause and effect. In contrast, Gourlan et al. [35] conducted a meta-analysis of theory-based interventions and concluded that the TTM was effective in promoting behavior change. However, no superiority was found for any theory's effectiveness in the analysis, and the TTM itself achieved a d value of 0.31 (using Cohen's d) [36], a value lower than that of two of its fellow theories, placing it in the category of small to moderate effect. Romain et al. [37] also provide support for the TTM's effectiveness when used properly, providing somewhat of a free pass for when success does not take place. It is accurate for Khan et al. [38] to state that the level of inactivity within society means that even a slight PA increase could have major positive health implications. However, we contend that slight increases alone are not something to strive for and continually fund, when there are more innovative and potentially successful approaches available to develop.

In addition to poor implementation, the TTM has been critiqued for several other reasons. Firstly, the model was created initially to tackle the addiction to smoking [20]. It was targeting cessation and abstinence, and thus differs from PA contexts which target adoption and adherence. The characteristics of the TTM consequently may not be appropriate to the adoption of PA, as highlighted by Rosen [39], who found inconsistencies in processes of change across differing health contexts. Hutchison, Johnston, and Breckon [40] (p. 110) also state that despite the evidence in the PA literature for processes of change, due to the "dominance of positivistic research practices ... (there have been) limited attempts to ascertain whether additional PA behavior change processes exist". Secondly, it has been argued that exercise behavior involves numerous factors, many of which are not accounted for by the TTM [34]. Adams and White [41] highlight that social factors such as age, gender, and socio-economic position are known to influence PA levels, yet find no place within this theoretical framework. In short, it fails to account for the plethora of likely unacknowledged independent variables acting as confounding variables. Third, it has been suggested that "PA is more complex than single behaviors such as smoking and that individuals could be in a number of different stages of change depending on the type of activity being considered" [41] (p. 830). Hutchison, Johnston, and Breckon [40] remind us that PA is highly variable; the degree to which people transform their exercise habits varies significantly between people. Finally, we would add that, following the idea of intersectionality, the notion of an independent variable is itself questionable because the highly contextualized combination of factors such as gender and socio-economic status leads to the emergence of a unique dynamic of its own, that cannot be 
isolated from the interaction between two variables. Thus, using such a generic model of change exposes researchers to the danger of underestimating the complexity of the interventions required to improve PA behavior. In summary, in spite of its operational complexities, we view the TTM as too simplistic and mechanistic to account for the complex process of modifying PA behavior. In addition to these concerns, we add a fourth. Many PA interventions based on the TTM, also rely on the ABC framework [13] for generating behavior change. The $A B C$ framework is also subject to a range of criticism, which we address next.

\subsection{The ABC Framework}

The ABC framework has been used within intervention research [42,43] and, historically, has played a key role within policy-based attempts to promote behavior change [44,45]. According to Shove [13] (p. 1274), "social change is thought to depend upon values and attitudes (the A), which are believed to drive the kinds of behavior (the B) that individuals choose (the $\mathrm{C}$ ) to adopt". The policy version differs slightly, using "context" rather than "choice" to account for " $\mathrm{C}$ ", in line with social psychologist Paul Stern [46]. In this way, the " $\mathrm{C}$ " usually represents a causal variable or barrier to change for an individual. However, Shove [13] maintains that since the $\mathrm{ABC}$ framework presumes that outcomes are a consequence of individual action, and individuals can choose to act differently, the " $\mathrm{C}$ " ultimately represents choice.

Despite the lack of explicit reference, many PA interventions are characterized by, and draw upon, the $\mathrm{ABC}$ framework. They work on the principle that by relieving barriers $(\mathrm{C})$ for populations, individuals' attitudes (A) and behaviors (B) will transform in a positive way. Examples include subsidizing costs and providing access to facilities and trainers [47]. However, the framework has been questioned for its inability to explain the value-action gap that is prevalent across a range of fields of activity in contemporary society [48]. Used heavily within sustainability research, this concept refers to the idea of "why do people fail to practice what they preach" [49] (p. 647). This is perhaps best illustrated today by inconsistencies between beliefs about the importance of fighting climate change and the environmentally harmful behaviors that often follow [50]. This attitude-behavior split has also been illustrated within PA research. Studies on subjective attitudes have suggested that certain barriers prevent PA participation. Yet when these are lifted, attitudes, behaviors, and choices have not evolved to the extent where we could speak of a successful transformation [51,52]. As Shove [13] (p. 1276) argues, "the (value-action) gap is only mystifying if we suppose that values do (or should) translate into action". Thus, continued investment in the ABC framework is likely to result in a limited understanding of social change.

We have highlighted how these theories are both conceptually and empirically limited. However, despite their well-publicized critiques and partial defenses, there is a continued investment in their ability to transform behavior across a multitude of levels, even as far as underpinning Sport England's [53] nationwide recommendations for tackling inactivity. From a more sociological perspective, the TTM and ABC frameworks perceive the agency structure relationship too simplistically, as one ultimately controlled by rational and autonomous individuals. Much like opposing perceptions which are based on macro, structural theories, they are consequently incapable of shedding light on the "social, affective, material and interrelational features of human activity" in between the ABC and throughout the social world altogether [54] (p. 159). We contend that identifying and removing these blind spots is necessary to advance PA promotion and really begin to tackle the "wicked problem" that intersectionality plays in this. Additionally, as pointed out by Spotswood et al. [12], reframing socio-cultural issues as moral responsibilities and placing the onus of responsibility for behavior change on individuals can magnify social stigma [55]. This individualizing conception of behavior change aligns itself with, and further legitimizes, socially Darwinistic neoliberal policy-making strategies and the symbolic violence associated with them, ignoring the complex issues that underpin human (in)activity and further enhancing social inequality $[54,56]$. We require more sophisticated accounts of how the social world comes to be, where the basic domain of enquiry "is neither the experience of the 
individual actor, nor the existence of any societal totality, but social practices ordered across space and time" [57] (p. 2). Accordingly, we turn to theories of practice.

\section{Theories of Practice: Principles and Practice}

Theories of practice emerged from the disciplines of philosophy and sociology as each attempted to resolve the problem of voluntarism/determinism and social structure/agency, respectively. Sociologically, norm-orientated action, by the homo sociologicus, explains the social world as governed by collective norms and values, and the social "ought" that is present in particular societies, while purpose-orientated action, by the homo economicus, individualizes subjective purposes and interests [58]. Where theories of practice excel is in their ability to shed light on the blind spot common in classical sociological theory, recognized by "1st generation practice theorists" such as Bourdieu [59] and Giddens [57], as an implicit, (barely) unconscious layer of knowledge which enables a symbolic organization of reality. In other words, they understand social order as embedded in collective cognitive, symbolic, and practical structures incorporated by individuals. Consequently, practice theory is claimed to be capable of bridging the gap between structure and agency [60], which is necessary to illuminate the "blind spot" in PA research.

Philosophically speaking, there are many precursors contributing to "the practice turn", including Wittgenstein, Heidegger and pragmatists such as John Dewey [61,62]. It was Theodore Schatzki, however, who breathed new life into the idea at the close of the twentieth century, with a novel take on practice theory as a site of ontology and also providing an influential theoretical vocabulary [63]. Schatzki's conceptions are being developed by a wide range of " 2 nd generation practices theorists" such as Andreas Reckwitz and Elizabeth Shove. Contemporary practice theory is being used in a wide range of disciplines, including geography [64], organizational studies [65], and sustainability [66,67].

"Practice theory" and "theories of practice" may be used interchangeably because there is no one conclusive theory, but rather a family of shared concepts and principles, as outlined by Schatzki [61] (p. 11):

Practice accounts are joined in the belief that such phenomena as knowledge, meaning, human activity, science, power, language, social institutions, and historical transformation occur within and are aspects or components of the field of practices.

Schatzki (Ibid) further contends that the field of practices represents the total nexus of interconnected human practices, commenting that "A central core, moreover, of practice theorists conceives of practices as embodied, materially mediated arrays of human activity centrally organized around shared practical understanding." Therefore, practice is generally agreed to be the site, nexus, suture, or interface between the individual and the social. Consequently, practice becomes the unit of analysis when studying the social world. According to Reckwitz [60] (p. 249), while the term "practice" represents the totality of human action, "a practice" refers to:

A routinised type of behavior which consists of several elements, interconnected to one another: forms of bodily activities, forms of mental activities, 'things' and their use, a background knowledge in the form of understanding, know-how, states of emotion and motivational knowledge.

A fundamental property of practice, and what makes it a site of ontology, is that it cannot be reduced to any one single element or variable, as the existence of practice necessarily depends on the co-existence and interconnectedness of the other elements, as Reckwitz highlights. To account for this, Schatzki [68] (p. 71) defines any given practice as a "bundle of activities" or an "organized nexus of actions". For example, recreational swimming involves the acquisition of the correct kit, transfer to a swimming pool, navigation of opening times, access to payment and the practice of payment, changing and showering practices, and of course the practice of swimming itself-to name a few elements. Any change to one of these elements will alter the others and consequently the practice 
itself. As Seith [69] highlights, particular ethnic minorities often shun recreational swimming-not the act of moving through water, but rather the normalized practices surrounding exposing the body in a public place. Therefore, the dispositional clash between the agent and one element of this "organized nexus of actions" modifies each of the aspects of this nexus and generates disengagement. However, this should not be viewed as an individual issue, but rather as a practice one. Similarly, it is just as plausible that young, disadvantaged women experience dispositional misalignment to particular elements of a given "organized nexus of actions" constituting PA practices. Importantly, this becomes the focus of exploratory and intervention research. Therefore, unlike behavior change models, practice theory approaches also have the advantage of de-individualizing the issue of inactivity while keeping individuals very much connected to the solution.

While Schatzki [70] refers to practice as a nexus of actions, he also distinguishes practice as a performance. This refers to the execution of practices which actualizes and sustains practices as entities. In other words, the reproduction of the nexus requires regular (re)enactment [71]. Building upon his earlier definition, Reckwitz's [60] (pp. 249-250) work goes on to describe how the elements of a practice are properties of the practice itself, and not the individual.

The single individual—as a bodily and mental agent—-then acts as the 'carrier' (Träger) of a practice-and, in fact, of many different practices which need not be coordinated with one another. Thus, she or he is not only a carrier of patterns of bodily behavior, but also of certain routinised ways of understanding, knowing how and desiring. These conventionalized 'mental' activities of understanding, knowing how and desiring are necessary elements and qualities of a practice in which the single individual participates, not qualities of the individual.

Practices are carried across space and time by the individual, and their existence depends on consistent incitement by carriers. The idea that features of practices are not individual attributes is a radical departure from more conventional theories which place these concepts within the realm of the agent [62]. For example, the physical and mental know-how, as well as the purpose of jogging are features of the practice of jogging. They must be adopted by a carrier for them to become competent practitioners of the activity. Schatzki's [68] concept of general understanding also illustrates how practices are not only understandable to the agent, but also to potential observers (at least within similar cultures). Practices thus become routinized ways in which the social world is performed, perceived, understood, and (re)constructed through action.

Summarizing our argument so far, a reliance on over-simplified models of the human-social interface, which assume smooth translations between compartmentalized stages, provides an insufficient account of the lively and potentially extended social processes that occur in between each stage of change. A singular causal focus on static structural or individual factors provides no space in which to explore the intricacies of social practice in everyday life. Practice theory, on the other hand, is capable of focusing on this and has proven effective within various fields. In particular, the work of Elizabeth Shove is where we see the most potential for translation into our own area of PA research.

A pressing matter within sustainability research surrounds how we can encourage and sustain individual behavior change toward more environmentally conscious choices in a convenience-driven consumer culture. Likewise, the key aim of most PA intervention work is to encourage and sustain active lifestyles among sedentary and resistant populations [72]. Therefore, like sustainability research, PA research is about fostering more positive practices, not simply terminating harmful ones. To translate Shove's notion of practice theory into the PA context, we have adopted and adapted three key propositions from Shove and Spurling's [66] (p. 1) discussion of social theory and climate change:

(a) Consumption is usefully understood as an outcome of practice: most people "consume" exercise and its associated elements not for their own sake but in the course of accomplishing practices.

(b) Transforming PA behavior within sedentary populations is sure to require different patterns of consumption of exercise and daily life. 
(c) Therefore, social theories of practice provide an important intellectual resource for understanding and constructing different social, institutional, and infrastructural conditions in which more positive exercise practices and healthier lifestyles may take hold.

From this standpoint, researchers need to understand how social practices affect how and why disadvantaged females consume PA, and how interventions need to focus on changing the nexus of social practices in their lives to encourage healthier forms of consumption in daily life. As stated above, in contrast to individualistically theorized TTM and ABC frameworks with their blind spots around value-action gaps - and hence why PA participation does not always improve with their use-practice theory is fundamentally social and designed for this purpose, as it contextualizes the ABC and TTM stages. Using practices as the key unit of analysis grants researchers a tangible insight into the social intricacies of daily life and brings previously abstract concepts (such as the value-action gap) to the forefront through the study of what individuals say and what they repeatedly do. A focus on social practice allows researchers to understand the elements of these practices that are both favorable and unfavorable for this population, as well as how to tailor the elements of PA accordingly for future participants. The final section of the paper outlines how specific practice theory concepts might be deployed to study the relationship between PA and young, disadvantaged women.

\section{Applying Practice Theory to Physical Activity Research: Theoretical Considerations}

\subsection{The Three Elements Model}

Shove, Pantzar, and Watson [62] developed the three elements model to simplify Reckwitz's [60] all-encompassing definition. Practices are said to consist of interdependent relations between materials, meanings, and competencies. Materials comprise objects, tools, infrastructure, hardware, and the body itself [73]. Meanings represent the "social and symbolic significance of participation in any one moment" [62] (p. 24), conversely represented by Reckwitz [60] as mental activities, emotion, and motivational knowledge, and by Schatzki [70] as teleoaffective structures. The difference being that here, meanings are constitutive of a practice, not something that stands outside of, or drives, one. Finally, competencies represent multiple forms of understanding and practical knowledgeability.

The three elements model operates on the assumption that practices are contextual and processual, emerging, persisting, shifting, and disappearing when links between materials, meanings, and competencies are made, sustained, or broken. Importantly, existing practices can cease to exist or modify when links begin to degrade. This might be due to new materials, meanings, or know-how rendering previous configurations redundant. For example, active travel practices have decreased since cars became accessible to the masses, and infrastructures built around the car have come to dominate local travel, rendering cycling as dangerous (meanings) and difficult to accomplish (competence) on congested streets, with relatively few cycle routes and places to lock bikes (materials) [74]. By contrast, the emergence of "spinning" from cycling and aerobics draws materials, meanings, and competencies from both and illustrates how new practices evolve from new relations between elements, which address the limitations of each (it is a safer, more predictable, and more efficient fitness activity in terms of time spent). Thus, we arrive at a situation where it "makes sense" to drive to the gym and cycle/spin, or drive to work or school to avoid risk and inconvenience. Spotswood et al. [12] (p. 6) also highlight how materials, meanings, and competencies can "hang together" in ways that inhibit PA participation for young females. The young women in their study reported that boys were unlikely to pass the ball to them during lunchtime soccer games. The physical resources to play were available, yet these materials were "meaningfully understood as being 'not for girls'-an understanding linked closely to their competence". Lunchtime football thus became a gendered "organized nexus of actions" whereby girls were often excluded, thereby lowering their activity levels and making them feel less inclined to pursue the sport elsewhere due to their lack of practice (and the concurrent development of empowering meanings and competencies).

In addition, the three elements model provides a framework to take the small things seriously. Minute elements of daily life, such as whether young females in the double jeopardy situation have the 
material resources (money, equipment, clothing, and so on) and competency/meanings to determine which are the "right" trainers for different types of PA, can have real impact on how they consume exercise. These details are too often overlooked when the focus is driven by TTM and ABC models that privilege notions of atomized individual choice. Embedding considerations of how materials, meanings, and competencies infiltrate subjectivity has the potential to reveal a more detailed and complex, yet realistic, picture of PA behavior. Spotswood et al. [12] have provided a strong example of how to set up a practice-based study using the three elements model. Following data collection, interventions can be designed to challenge existing "organized nexuses of actions", providing or subtracting materials, enhancing specific competencies, and shifting meanings. Moreover, a practice understanding of how these women consume PA will more likely provide practical solutions. As PA providers, this will allow us to tailor our provision more effectively and engage in continuous conversations with participants surrounding what practice elements facilitate and inhibit their participation in PA. As Spotswood et al. conclude, analyses which account for the interactions between elements of practice enable us to produce a "complex but rigorous web of interrelating factors which can form the basis for a multi-layered behavior change strategy" to the benefit of those experiencing the double jeopardy [74] (p. 30).

On a critical-reflective note, Shove, Watson, and Spurling [75] also critique their own three elements model, noting that while it can conceptualize the bounded objects with which practitioners interact (such as sports kit, gym equipment, or bicycles), the limitation of the model is that it is not yet as capable as it needs to be of explaining the co-existing forms of materiality within which these objects function. They propose Schatzki's [76] "material arrangements" as a more appropriate tool for understanding diverse configurations such as infrastructure. While the concept of material arrangements is broader and normally located outside of the immediacies of specific practice nexuses-they are what practices transpire amidst a material context-unlike the three elements model, which places materiality as a core element of practice. Thus, Schatzki's concept does not differentiate between a material's background role (the road, bicycle lanes, and so on) and more blatant roles mobilized in the conduct of a practice (the bicycle itself). This is potentially problematic when we need to understand how broad systems like material infrastructure are implicated in the conduct of multiple social practices, as is likely with our research population and PA (such as the material arrangement of a cycle lane). Addressing this, Shove, Watson, and Spurling [75] identify four characteristics of material infrastructure: (1) connective and extensive; (2) they sustain a range of different practices at once; (3) they are collective; and (4) they are relatively obdurate. These conceptual elaborations provide a more nuanced understanding of how materials co-exist with, and influence, social practices, as well providing a material context to PA research studies. A prime example of this is the way in which cycling lanes and pathways often provide incomplete routes and do not offer safe pathways which make them less likely to be used by disadvantaged female populations. This issue was recognized in Spotswood et al.'s analysis of cycling as social practice, whereby fears over safety inhibited the adoption of cycling as a viable activity for a young mother, and committed cyclists were perceived to be "brave" and "adventurous", characteristics that may not be relatable to much of society [74] (p. 26).

\subsection{Ancillary Concepts}

There are further sensitizing concepts around practice theory that offer additional heuristic devices to understand the relationship between PA and young, disadvantaged women. Specifically, these include "anchoring practices" and "affective practice".

Swidler's [77] "anchoring practices" describe how certain practices can anchor or govern others. For example, in contrast to enthusiastic cyclists whose working day might be anchored to the cycle commute, a consistent finding of many studies into barriers to women's PA participation is their reporting of a fundamental conflict between being active and being feminine [78], with cycle commuting disrupting feminine practices. Interpreting this from a practice perspective suggests that the "anchoring" practice here surrounds "being feminine" or "being a woman" and the practices as performances that surround these meanings and competencies. Because practices surrounding femininity take precedence 
over being physically active in the ways in which activities like cycle commuting demand, these restrain which PA practices are performed when these females choose to be active, if they choose to be active at all. Therefore, PA interventions need to account for anchoring practices and their mitigating impacts on PA. Young females in double jeopardy may also experience another anchoring practice around financing PA, whereby limited personal and family funds are reserved for other governing practices, such as those surrounding earning money for food and basic clothing. Costs of many types of PAs are likely to be considered against these even if they are "affordable" (in the sense that this leaves less money spent on the anchoring practices). Evidence is also provided by Spotswood et al. [12], whereby the practice of walking to school was found to largely depend upon being in harmony with the routines and goals of the parent/guardian. Educational and occupational practice, specifically arriving on time, governed travel practices and rendered walking as too time-consuming and undesirable for certain families, illustrating how one practice is anchored to (and hence ordered, and in these examples, subordinated, by another). Anchoring practices can play a key role in "reproducing larger systems of discourse and practice" and, in certain circumstances, "practices can anchor or reproduce constitutive rules that define things as what they are" [77] (p. 99). Therefore, anchoring practices need to be included in studies in order to identify the key practices that anchor individuals' daily lives and how subsequent PA practices are ordered in relation to these.

Second, we propose a further sensitivity towards Wetherell's [79] (p. 147) concept of affective practice, which is "an ongoing flow (a 'poly-phony' according to Damasio [80]) of forming and changing body-scapes, qualia (subjective states), and actions constantly shifting in response to the changing context". The term is useful to explain how certain practices are laden with affective properties. For example, the practice of cycle commuting to work or school often involves getting hot, sweaty, or wet. How these emergent subjective states are culturally contextualized and given meaning among groups such as disadvantaged females becomes of central importance. According to Reckwitz [81], the presence of affect in society cannot be ignored, as it is a constitutive part of social life enlivened by practice. He contends that every practice is "affectively tuned in a particular way and has ... a built-in affective dimension" (p. 118). Similar to Reckwitz's [60] earlier conception of how activities such as know-how, understanding, and desiring are components of the practice and not the individual, here affects are "properties of the specific affective 'attunement' or mood of the respective practice" [81] (p. 119). Once an individual becomes competent in a given practice, they incorporate and actualize its mood (somatization through practical socialization and enculturation), and thus distinct moods constitute each practice. An example of this might be the affective response to becoming wet or hot and sweaty during a cycle commute or an exercise class. Such subjective states are not only accommodated but even embraced by commuters and exercisers as positive elements of their chosen activity - a sign of having acquired the appropriate meanings and competencies through the practice of the practice. However, for those unaccustomed or unprepared, such bodily and subjective states which emerge through practice can have very different affects, particularly when these clash with other states induced by other anchoring practices (for example wanting to appear traditionally feminine or not being in a position to purchase the necessary equipment and clothing to render these bodily states less uncomfortable and thereby negatively affective). Using this concept will also mean questioning what moves us to perform PA, how affective atmospheres, spaces, and generators [81,82] affect our participation, and what particular elements of PA bring about such positive and negative affects, thereby shaping meanings. While the use of practice theory in this way might seem to de-individualize the subject, the deeper purpose of this approach, in keeping with generations of practice theorists beginning with Mauss, Bourdieu, Giddens, and, more recently, Shove, Reckwitz, and Schatzki is to circumvent dualistic notions of subjectivism and objectivism. Subjectivities are kept very much at the forefront of the research (and its practical solutions) by taking individual affects into account but without collapsing into solipsistic interpretations of these. Rather, these emergent subjectivities are recognized to be constituted by myriad practices, differentiated by the intersections of social class, gender, ethnicity, sexuality, ability, health, age, and so on. This recognition shifts the perspective away 
from affects as individualized mental or physical properties and toward studying them as constitutive of, and emergent from, structured daily PA practice (diverse though these may be).

\section{Conclusions}

In summary, this paper has argued that, while not without value, many PA intervention studies over-rely on behavior change models, such as the TTM and ABC framework. We have argued that a sequential and compartmentalized conceptualization of the process of behavior change does not readily reflect the dynamic process of behavior change that comes to light when social context and processes are also considered. The onus of responsibility on erroneously configured atomized rational actors, enjoying unbridled choice and agency, is indicated by the lack of outright success of interventions $[83,84]$ and the value-action gap identified by Shove [13] in ABC-inspired behavior change research and policy interventions. In order to move away from such models, we proposed a move toward using practices as the key unit of social analysis, alongside the idea that individuals are carriers and performers of practices.

In contrast, the practice theory approach advocated here means seeking out the all-too-infrequently visited middle ground between structural constraint/opportunity, agentic freedom, and interrogating the dynamic mediations between the two that emerge from our everyday practices. We provided an overview of key elements of practice theory while highlighting the appropriateness and potential for exploring the double jeopardy relationship between PA and young, disadvantaged women. We have highlighted areas that exploratory/intervention studies might focus on to identify and transform the three constitutive elements of practice, namely meaning, materials, and competencies [62] in PA contexts, alongside the ancillary concepts of anchoring practices [77] and affective practice [79].

As Hui [85] (p. 99) suggests, a practice-based intervention cannot operate with a "business as usual" attitude, and researchers will have to account for the winners and losers when manipulating elements of practice. This does not have to be negative, however. "Blanket" approaches that ostensibly remove barriers to PA are often guilty of continuing to offer the same activities that have been consistently disengaged from. Evidence suggests that the practice of specific rules of activity engagement, as well as those surrounding uniforms, settings, objects, and so on, inhibit PA participation within particular groups. Practice theory provides us with the conceptual means to both explore and transform these inhibiting elements in practical, meaningful ways, potentially challenging and shifting the anchoring practices and their affects.

We conclude that approaching the double jeopardy intersection through the lens of practice theory has the potential to address some of the major limitations present in the behavioral change models used for typical PA intervention work. Despite successful implementation elsewhere [86,87], much work remains to build on Blue [11] and Spotswood et al.'s [12] work and adapt practice theory more fully to the PA domain. We are confident, however that the increased use of practice theory will contribute significantly to participation levels by providing more practical and workable heuristics, for participants and providers alike.

Author Contributions: Conceptualization, E.H., D.B., N.B.; writing—original draft preparation, E.H.; writing—review and editing, E.H., D.B., N.B., N.M.; funding acquisition N.B., M.A. All authors have read and agreed to the published version of the manuscript.

Funding: This research was funded by a KESS2 Knowledge Economy Skills Scholarship, in partnership with Valleys Gymnastics Academy.

Conflicts of Interest: The authors declare no conflict of interest. The funders had no role in the design of the study; in the collection, analyses, or interpretation of data; in the writing of the manuscript, or in the decision to publish the results.

\section{References}

1. Vuori, I. World Health Organization and Physical Activity. Prog. Prev. Med. 2018, 3, e0012. [CrossRef]

2. Musich, S.; Shaohung, S.W.; Hawkins, K.; Greame, C. The Frequency and Health Benefits of Physical Activity for Older Adults. Popul. Health Manag. 2016, 20, 199-207. [CrossRef] [PubMed] 
3. Pratt, M.; Varela, A.R.; Salvo, D.; Kohl iii, H.W.; Ding, D. Attacking the Pandemic of Physical Inactivity: What is Holding Us Back? Br. J. Sports Med. 2019. [CrossRef]

4. Sport England. Demographic Knowledge: Target Groups. 2019. Available online: https://www.sportengland. org/know-your-audience/demographic-knowledge (accessed on 15 August 2020).

5. Crenshaw, K. Demarginalizing the Intersection of Race and Sex: A Black Feminist Critique of Antidiscrimination Doctrine, Feminist Theory and Antiracist Politics. Univ. Chicago Legal Forum. 1989, 1, 139-167.

6. StreetGames. Us Girls Wales Programme Report, 2015-2017; Sport Wales and StreetGames: Cardiff, UK, 2017.

7. Economic and Social Research Council. Poorer People Are Less Physically Active; Economic and Social Research Council: Swindon, UK, 2014.

8. The Lancet. Time to Tackle the Physical Activity Gender Gap. Lancet Public Health 2019, 4, 360. [CrossRef]

9. Sport England. Active Lives Adult Survey; Sport England: London, UK, 2019.

10. NHS Digital. Statistics on Obesity, Physical Activity and Diet, England, 2019. Available online: https://digital.nhs.uk/data-and-information/publications/statistical/statistics-on-obesity-physical-activityand-diet/statistics-on-obesity-physical-activity-and-diet-england-2019/part-5-adult-physical-activity (accessed on 25 June 2020).

11. Blue, S. Maintaining Physical Exercise as a Matter of Synchronizing Practices: Experiences and Observations from Training in Mixed Martial Arts. Health Place 2017, 46, 344-350. [CrossRef]

12. Spotswood, F.; Wiltshire, G.; Spear, S.; Morey, Y.; Harris, J. A Practice Theory Approach to Primary School Physical Activity: Opportunities and Challenges for Intervention. Crit. Public Health 2019. [CrossRef]

13. Shove, E. Beyond the ABC: Climate Change Policy and Theories of Social Change. Environ. Plan. 2010, 42, 1273-1285. [CrossRef]

14. Whitehead, S.; Biddle, S. Adolescent Girls' Perceptions of Physical Activity: A Focus Group Study. Eur. Phys. Educ. Rev. 2008, 14, 243-262. [CrossRef]

15. Fernandez, I.; Canet, O.; Gine-Garriga, M. Assessment of Physical Activity Levels, Fitness and Perceived Barriers to Physical Activity Practice in Adolescents: Cross Sectional Study. Eur. J. Pediatr. 2017, 176, 57-65. [CrossRef]

16. Uddin, R.; Burton, N.W.; Khan, A. Perceived Environmental Barriers to Physical Activity in Young Adults in Dhaka City, Bangladesh-Does Gender Matter? Int. Health 2018, 10, 40-46. [CrossRef] [PubMed]

17. Collins, M.F.; Kay, T. Sport and Social Exclusion, 2nd ed.; Routledge: New York, NY, USA, 2014.

18. Craike, M.; Wiesner, G.; Hilland, T.A.; Bengoechea, E.G. Interventions to Improve Physical Activity Among Socioeconomically Disadvantaged Groups: An Umbrella Review. Int. J. Behav. Nutr. Phys. Act. 2018, 15, 43-54. [CrossRef] [PubMed]

19. Cleland, C.L.; Hunter, R.F.; Tully, M.A.; Scott, D.; Kee FDonnelly, M.; Prior, L.; Cupples, M.E. Identifying Solutions to Increase Participation in Physical Activity Interventions Within a Socio-Economically Disadvantaged Community: A Qualitative Study. Int. J. Behav. Nutr. Phys. Act. 2014, 11, 68-77. [CrossRef]

20. Prochaska, J.O.; DiClemente, C.C. Stages and Processes of Self-Change of Smoking: Toward an Integrative Model of Change. J. Consult. Clin. Psychol. 1983, 51, 390-395. [CrossRef]

21. Choi, J.; Lee, J.H.; Vittinghoff, E.; Fukuoka, Y. Health Physical Activity Intervention: A Randomized Pilot Study in Physically Inactive Pregnant Women. Matern. Child Health J. 2015, 20, 1091-1101. [CrossRef] [PubMed]

22. Strachan, S.M.; Marcotte, M.M.E.; Giller, T.M.T.; Brunet, J.; Schellenberg, B.J.I. An Online Intervention to Increase Physical Activity: Self-Regulatory Possible Selves and the Moderating Role of Task Self-Efficacy. Psychol. Sport Exerc. 2017, 31, 158-165. [CrossRef]

23. Lubans, D.; Morgan, P.; Weaver, K.; Callister, R.; Dewar, D.; Costigan, S.; Finn, T.; Smith, J.; Upton, L.; Plotnikoff, R. Rationale and Study Protocol for the Supporting Children's Outcome Using Rewards, Exercise and Skills (SCORES) Group Randomized Controlled Trial: A Physical Activity and Fundamental Movement Skills Intervention for Primary Schools in Low-Income Communities. BMC Public Health 2012, 12, 427-438. [CrossRef]

24. Rowland, S.A.; Berg, K.E.; Kupzyk, K.A.; Pullen, C.H.; Cohen, M.Z.; Schulz, P.S.; Yates, B.C. Feasibility and Effect of a Peer Modelling Workplace Physical Activity Intervention for Women. Workplace Health Saf. 2018, 66, 428-436. [CrossRef] 
25. Camacho-Minano, M.J.; LaVoi, N.M.; Barr-Anderson, D.J. Interventions to Promote Physical Activity among Young and Adolescent Girls: A Systematic Review. Health Educ. Res. 2011, 26, 1025-1049. [CrossRef]

26. Gu, X.; Chen, Y.; Jackson, A.W.; Zhang, T. Impact of a Pedometer-Based Goal Setting Intervention on Children's Motivation, Motor Competence, and Physical Activity in Physical Education. Phys. Educ. Sport Pedagog. 2018, 23, 54-65. [CrossRef]

27. Miller, B.G.; Valbuena, D.A.; Zerger, H.M.; Miltenberger, R.G. Evaluating Public Posting, Goal Setting and Rewards to Increase Physical Activity During School Recess. Behav. Intent. 2018, 33, 237-250. [CrossRef]

28. Prochaska, J.O.; DiClemente, C.C.; Norcross, J.C. In Search of How People Change: Application to Addictive Behaviors. Am. Psychol. 1992, 47, 1102-1114. [CrossRef] [PubMed]

29. Johnson, S.S.; Paiva, A.L.; Cummins, C.O.; Johnson, J.L.; Dyment, S.J.; Wright, J.A.; Prochaska, J.O.; Prochaska, J.M.; Sherman, K. Transtheoretical Model-Based Multiple Behavior Intervention for Weight Management: Effectiveness on a Population Basis. Prev. Med. 2008, 46, 238-246. [CrossRef] [PubMed]

30. Robinson, L.M.; Vail, S.R. An Integrative Review of Adolescent Smoking Cessation Using the Transtheoretical Model of Change. J. Paediatr. Health Care 2012, 26, 336-345. [CrossRef]

31. Adams, J.; White, M. Are Activity Promotion Interventions Based on the Transtheoretical Model Effective? A Critical Review. Br. J. Sports Med. 2003, 37, 106-114. [CrossRef]

32. Bridle, C.; Riemsma, R.P.; Pattenden, J.; Sowden, A.J.; Mather, L.; Watt, I.S.; Walker, A. Systematic Review of the Effectiveness of Health Behavior Interventions Based on the Transtheoretical Model. Psychol. Health 2005, 20, 283-301. [CrossRef]

33. Callaghan, P.; Khalol, E.; Morres, I. A Prospective Evaluation of the Transtheoretical Model of Change Applied to Exercise in Young People. Int. J. Nurs. Stud. 2010, 47, 3-12. [CrossRef]

34. Hutchison, A.J.; Breckon, J.D.; Johnston, L.H. Physical Activity Behavior Change Interventions Based on the Transtheoretical Model: A Systematic Review. Health Educ. Behav. 2009, 36, 829-845. [CrossRef]

35. Gourlan, M.; Bernard, P.; Bortolon, C.; Romain, A.J.; Lareyre, O.; Carayol, M.; Ninot, G.; Boiche, J. Efficacy of Theory-Based Interventions to Promote Physical Activity. A Meta-Analysis of Randomized Control Trials. Health Psychol. Rev. 2016, 10, 50-66. [CrossRef]

36. Cohen, J. Statistical Power Analysis for the Behavioral Sciences; Routledge: New York, NY, USA, 1988.

37. Romain, A.J.; Bortolon, C.; Gourlan, M.; Carayol, M.; Decker, E.; Lareyre, O.; Ninot, G.; Boiche, J.; Bernard, P. Matched or Nonmatched Interventions Based on the Transtheoretical Model to Promote Physical Activity: A Meta-Analysis of Randomized Controlled Trials. J. Sport Health Sci. 2018, 7, 50-57. [CrossRef]

38. Khan, K.M.; Thompson, A.M.; Blair, S.N.; Sallis, J.F.; Powell, K.E.; Bull, F.C.; Baumann, A.E. Sport and Exercise as Contributors to the Health of Nations. Lancet 2012, 380, 59-64. [CrossRef]

39. Rosen, C.S. Is the Sequencing of Change Processes by Stage Consistent Across Health Problems? Health Psychol. 2000, 19, 593-604. [CrossRef]

40. Hutchison, A.J.; Johnston, L.H.; Breckon, J.D. A Grounded Theory of Successful Long-Term Physical Activity Behavior Change. Qual. Res. Sport Exerc. Health 2013, 5, 109-126. [CrossRef]

41. Adams, J.; White, M. Why Don't Stage-Based Activity Promotion Interventions Work? Health Educ. Res. 2005, 20, 237-243. [CrossRef]

42. Day, B.A.; Smith, W.A. The Applied Behavior Change (ABC) Framework: Environmental Implications. Adv. Educ. 1996, 1, 5-9.

43. Zohar, D.; Luria, G. The Use of Supervisory Practices as Leverage to Improve Safety Behavior: A Cross-Level Intervention Study. J. Saf. Res. 2003, 34, 567-577. [CrossRef] [PubMed]

44. Prendergast, J.; Foley, B.; Menne, V.; Issac, A.K. Creatures of Habit: The Art of Behavioral Change; Social Market Foundation: London, UK, 2008.

45. Department for Environmental, Food and Rural Affairs. A Framework for Pro-Environmental Behaviors; Department for Environmental, Food and Rural Affairs: London, UK, 2008.

46. Stern, P. Toward a Coherent Theory of Environmentally Significant Behavior. J. Soc. Issues 2000, 56, 407-424. [CrossRef]

47. Choitz, P.; Johnson, M.P.; Berhane, Z.; Lefever, G.; Anderson, J.K.; Eiser, A.R. Urban Fitness Centers: Removing Barriers to Promote Exercise in Undeserved Communities. J. Health Care Poor Undeserved 2010, 21, 221-228. [CrossRef]

48. Blake, J. Overcoming the Value-Action Gap in Environmental Policy: Tensions between National Policy and Local Experience. Local Environ. 1999, 4, 257-278. [CrossRef] 
49. Smith, J.R.; Louis, W.R. Do as We Say and as We Do: The Interplay of Descriptive and Injunctive Group Norms in the Attitude-Behavior Relationship. Br. J. Soc. Psychol. 2008, 47, 647-666. [CrossRef]

50. Babutsidze, Z.; Chai, A. Look at Me Saving the Planet! The Imitation of Visible Green Behavior and its Impact on the Climate Value-Action Gap. Ecol. Econ. 2018, 146, 290-303. [CrossRef]

51. Keyserling, T.C.; Samuel-Hodge, C.D.; Jilcott, S.B.; Johnston, L.F.; Garcia, B.A.; Gizlice, Z.; Gross, M.D.; Savinon, C.E.; Bangdiwala, S.I.; Will, J.C.; et al. Randomised Trial of a Clinic-Based, Community-Supported, Lifestyle Intervention to Improve Physical Activity and Diet: The North Carolina Enhanced WISEWOMAN Project. Prev. Med. 2008, 46, 499-510. [CrossRef] [PubMed]

52. Bull, E.R.; Dombrowski, S.U.; McCleary, N.; Johnston, M. Are Interventions for Low-Income Groups Effective in Changing Healthy Eating, Physical Activity and Smoking Behaviors? A Systematic Review and Meta-Analysis. BMJ Open 2014, 4, e006046. [CrossRef]

53. Sport England. Applying Behavior Change Theories: Real World Examples from the Get Healthy Get Active Projects. 2019. Available online: https://sportengland-production-files.s3.eu-west-2.amazonaws.com/s3fspublic/applying-behaviour-change-theories-real-world-examples-from-ghga.pdf (accessed on 20 July 2020).

54. Cohn, S. From Health Behaviors to Health Practices: An Introduction. Sociol. Health Illn. 2014, 36, 157-162. [CrossRef]

55. LeBesco, K. Neoliberalism, Public Health and the Moral Perils of Fatness. Crit. Public Health 2011, 21, 153-164. [CrossRef]

56. Katz, J.; Gravelin, C.R.; O’Brien, C. Neoliberal Beliefs and Perceptions of Unintended Adolescent Pregnancy after Consensual or Forced Sex. Sex Roles 2018, 78, 810-821. [CrossRef]

57. Giddens, A. The Constitution of Society: Outline of a Theory of Structuration; Polity: Cambridge, UK, 1984.

58. King, A. Structure and Agency. In Chapter 10 in Modern Social Theory: An Introduction; Harrington, A., Ed.; Oxford University Press: Oxford, UK, 2004.

59. Bourdieu, P. Outline of a Theory of Practice; Cambridge University Press: Cambridge, UK, 1972.

60. Reckwitz, A. Toward a Theory of Social Practices: A Development in Culturalist Thinking. Eur. J. Soc. Theory 2002, 5, 243-263. [CrossRef]

61. Schatzki, T. Introduction: Practice Theory. In The Practice Turn in Contemporary Theory; Schatzki, T., Cetina, K.K., Savigny, E.V., Eds.; Routledge: London, UK, 2001; pp. 10-23.

62. Shove, E.; Pantzar, M.; Watson, M. The Dynamics of Social Practice: Everyday Life and how it Changes; SAGE: London, UK, 2012.

63. Everts, J.; Lahr-Kurten, M.; Watson, M. Practice Matters! Geographical Inquiry and Theories of Practice. Erkunde 2011, 65, 323-334. [CrossRef]

64. Brzenczek, K.; Wiegandt, C.C. Peculiarities in the Visual Appearance of German Cities: About Locally Specific Routines and Practices in Urban Design Related Governance. Erkunde 2009, 63, 245-255. [CrossRef]

65. Gherardi, S. How to Conduct a Practice-Based Study: Problems and Methods; Edward Elgar Publishing: Gloucester, UK, 2012.

66. Shove, E.; Spurling, N. Sustainable Practices: Social Theory and Climate Change; Routledge: London, UK, 2013.

67. Hui, A.; Schatzki, T.; Shove, E. The Nexus of Practices: Connections, Constellations and Practitioners; Routledge: London, UK, 2017.

68. Schatzki, T. The Site of the Social: A Philosophical Account of the Constitution of Social Life and Change; The Pennsylvania University State Press: University Park, PA, USA, 2002.

69. Seith, E. Ethnic Minority Women Dive into Swimming Lessons. Times Education Supplement Scotlandl. 2013, 2301,6 .

70. Schatzki, T. Social Practice: A Wittgensteinian Approach to Human Activity and the Social; Cambridge University Press: New York, NY, USA, 1996.

71. Warde, A. What Sort of Practice is Eating? In Sustainable Practices: Social Theory and Climate Change; Shove, E., Spurling, N., Eds.; Routledge: Abingdon, UK, 2013; pp. 17-30.

72. Aghdam, F.B.; Sahranavard, H.; Jahangiry, L.; Jafarabadi, M.A.; Koushaa, A. The Effect of a Physical Activity Intervention on Sedentary Behavior in Female Teachers: A Randomized Control Trial. Health Scope 2018, 7, e68267.

73. Shove, E.; Watson, M.; Hand, M.; Ingram, J. The Design of Everyday Life; Bloomsbury: Oxford, UK, 2007.

74. Spotswood, F.; Chatterton, T.; Tapp, A.; Williams, D. Analysing Cycling as a Social Practice: An Empirical Grounding for Behavior Change. Transp. Res. Part F Traffic Psychol. Behav. 2015, 29, 22-33. [CrossRef] 
75. Shove, E.; Watson, M.; Spurling, N. Conceptualizing Connections: Energy Demand, Infrastructures and Social Practices. Eur. J. Soc. Theory 2015, 18, 274-287. [CrossRef]

76. Schatzki, T. The Timespace of Human Activity: On Performance, Society and History as Indeterminate Teleological Events; Lexington Books: Lanham, MD, USA, 2010.

77. Swidler, A. What Anchors Cultural Practices. In The Practice Turn in Contemporary Theory; Schatzki, T., Cetina, K.K., Savigny, E.V., Eds.; Routledge: London, UK, 2001; pp. 83-101.

78. Alvarinas-Villaverde, M.; Lopez-Villar, C.; Fernandez-Villarino, M.A.; Alvarez-Esteban, R. Masculine, Feminine and Neutral Sports: Extracurricular and Sport Modalities in Practice. J. Hum. Sport Exerc. 2017, 12, 1278-1288. [CrossRef]

79. Wetherell, M. Trends in the Turn to Affect. Body Soc. 2015, 21, 139-166. [CrossRef]

80. Damasio, A. The Feeling of What Happens: Body and Emotion in the Making of Consciousness; Harcourt: New York, NY, USA, 1999.

81. Reckwitz, A. Practices and their Affects. In The Nexus of Practices: Connections, Constellations and Practitioners; Hui, A., Shove, E., Schatzki, T., Eds.; Routledge: Oxford, UK, 2017; pp. 114-126.

82. Duff, C. On the Role of Affect and Practice in the Production of Place. Environ. Plan. D Soc. Space 2010, 28, 881-895. [CrossRef]

83. Han, H.; Gabriel, K.P.; Kohl, H.W., III. Applications of the Transtheoretical Model to Sedentary Behaviors and Its Association with Physical Activity Status. PLoS ONE 2017, 12, e0176330. [CrossRef] [PubMed]

84. Abula, K.; Gropel, P.; Chen, K.; Beckmann, J. Does Knowledge of Physical Activity Recommendations Increase Physical Activity among Chine College Students? Empirical Investigations Based on the Transtheoretical Model. J. Sport Health Sci. 2018, 7, 77-82. [CrossRef]

85. Hui, A. Practices, Movement and Circulation. In Sustainable Practices: Social Theory and Climate Change; Shove, E., Spurling, N., Eds.; Routledge: Oxford, UK, 2013; pp. 89-102.

86. Hargreaves, T. Practice-Ing Behavior Change: Applying Social Practice Theory to Pro-Environmental Behavior Change. J. Consum. Cult. 2011, 11, 79-99. [CrossRef]

87. McHardy, J. The Making of Electric Cycling. In Sustainable Practices: Social Theory and Climate Change; Shove, E., Spurling, N., Eds.; Routledge: Oxford, UK, 2013; pp. 132-145.

Publisher's Note: MDPI stays neutral with regard to jurisdictional claims in published maps and institutional affiliations.

(C) 2020 by the authors. Licensee MDPI, Basel, Switzerland. This article is an open access article distributed under the terms and conditions of the Creative Commons Attribution (CC BY) license (http://creativecommons.org/licenses/by/4.0/). 